\title{
IMPACTO DEL TURISMO NOSTÁLGICO Y LAS REMESAS FAMILIARES EN EL DESARROLLO DE COMUNIDAD RURAL OAXAQUEÑA*
}

\author{
RAFAEL G. REYES MORALES, ${ }^{* *}$ NYDIA DELHÍ MATA SÁNCHEZ, ${ }^{* * *}$ \\ ALICIA SYLVIA GIJÓN-CRUZ, ${ }^{* * *}$ ANDRÉS C. CRUZ CONTRERAS ${ }^{* * * * *}$ \\ Y SALVADOR LÓPEZ PLATAS $S^{* * * * *}$
}

RESUMEN: Se evalúan los impactos de la derrama económica del turismo nostálgico versus los impactos de las remesas familiares internacionales en San Francisco Cajonos, Oaxaca una comunidad zapoteca. Los hallazgos más relevantes son: las remesas familiares internacionales elevan el consumo de los hogares, mientras que la derrama económica incentiva producción local. Sin embargo, en los dos casos crece la dependencia con la región porque esta comunidad, por una parte, carece de instituciones financieras que reciclen la liquidez generada por la migración, el turismo nostálgico y los subsidios de gobierno; y, por otra, no produce bienes y servicios suficientes para satisfacer la demanda local. Aunque el turismo nostálgico constituye una oportunidad real para fortalecer la economía local, enfrenta las debilidades del turismo convencional: la estacionalidad de la fluencia de turistas nostálgicos y la corta duración de su estadía. Asimismo, se requieren inversiones en servicios para incrementar la derrama económica.

PALABRAS CLAVES: Turismo nostálgico, derrama económica, remesas familiares, impactos económicos, crecimiento económico.

ABSTRACT: Economic impacts of international family remittances are evaluated versus those of nostalgia tourism earnings in San Francisco Cajonos, Oaxaca a Zapotec community. The most relevant findings are: international family remittances raise households' consumption, while nostalgia tourism earnings encourage local production. However, in both cases dependence on the region grows because this community, on one hand, lacks of financial institutions that recycle liquidity generated by migration, nostalgia tourism and government subsidies; and, on the other, she does not produce goods and services enough to meet the local demand. Although nostalgia tourism represents a real opportunity to strengthen the local economy, it faces the weaknesses of conventional tourism: the seasonal nature of influx of nostalgia tourists and a short length of their stay. In addition, investments in services are required to increase nostalgia tourism earnings.

KEY wORDs: Nostalgia tourism, nostalgia tourism earnings, family remittances, economic impacts, economic growth.

* Los resultados presentados proceden del proyecto «Comunidades transnacionales MéxicoEstados Unidos. Caso Oaxaca (Regiones: Valles Centrales y Sierra Norte)», periodo 2004-2006, financiado por la Fundación Rockefeller (grant number: 2004NA021). Los autores quieren hacer un merecido reconocimiento a Rigoberto Ruiz Palacios, Diego Pérez Bennets, Nancy Y. Vivas Hernández, Martha M. López Chavez y Renato Salas Alfaro, quienes participaron tanto en actividades de trabajo de campo como en el procesamiento de las encuestas.

** Profesor investigador, Laboratorio de Estudios Regionales y Urbanos, Instituto Tecnológico de Oaxaca, e-mail: ragaremo@gmail.com

*** Estudiante de maestría y ayudante de investigación, Laboratorio de Estudios Regionales y Urbanos, Instituto Tecnológico de Oaxaca, samany30@gmail.com

**** Investigadora en el área de migración y desarrollo en el Instituto Tecnológico de Oaxaca, becada por la Fundación Rockefeller; y profesor de medio tiempo de la Universidad Autónoma Benito Juárez de Oaxaca. e-mail: gijoncruz@gmail.com

***** Investigador del Instituto Tecnológico de la Cuenca del Papaloapam e investigador becario en el Instituto Tecnológico de Oaxaca e-mail: acuatemo@gmail.com

****** Profesor del Centro de Estudios Tecnológicos Industrial y de Servicios 124 e investigador becario en el Instituto Tecnológico de Oaxaca, e-mail: salop25@gmail.com 


\section{INTRODUCCIÓN}

pesar del incremento impresionante a nivel mundial de la migración,
se han hecho pocos esfuerzos por estudiar el turismo nostálgico y los
impactos de su derrama en las economías locales. Esto se debe, en
parte, al excesivo énfasis que los gobiernos y los organismos financieros internacionales han hecho en las remesas y, como consecuencia, han eclipsado otros procesos económicos relevantes ligados a la migración. En parte, se debe también a que los instrumentos metodológicos para medir el impacto económico del turismo nostálgico son prácticamente inexistentes. Hasta ahora los estudios migratorios se han concentrando en subrayar su importancia y han puesto menos atención en su conceptualización (Candor, 2005: 44; Orozco 2005; Reyes Morales, Gijón Cruz et al. 2004: 217-221; Guarnizo, 2003). En cambio, existen estudios que miden con precisión los impactos económicos del turismo convencional en varias partes del mundo (Saluja, Pradhan y Singh, 2006; World Bank, 2003; World Bank, 2002; Gartner y David W., 2000; Wagner, 1996). Dentro de la gran diversidad de estudios de migración el enfoque trasnacional aporta elementos teóricos para construir un concepto amplio del turismo nostálgico como parte del proceso migratorio México-Estados Unidos en dos sentidos (Vortevec, 2006; Portes, 2005; Moctezuma 2005; Peggy Levitt y Schiller, 2004; Delgado Wise, 2004; Portes, 2003; Lozano, 2003). Las herramientas disponibles para medir los impactos económicos de las remesas en las comunidades de origen son las matrices de contabilidad social y los modelos multisectoriales (Taylor y Adelman, 1996; Sadoulet y De Janvry, 1995; Robinson et al., 1993); éstos también son útiles para medir el impacto de la derrama del turismo nostálgico asociado al dinero que traen consigo los migrantes cuando visitan sus comunidades de origen y que gastan durante su estancia. El turismo nostálgico presenta las mismas características que el turismo convencional y también en su comportamiento estacional durante el año. Por lo tanto, el herramental analítico del turismo convencional se puede aprovechar muy bien.

En particular, el turismo nostálgico es de gran importancia para el estado de Oaxaca, en donde la gente posee una fuerte identidad comunitaria basada en la familia, la religión católica (fiestas patronales), el sistema de cargos y prácticas de ayuda mutua (guelaguetza, compadrazgo). En este contexto, los migrantes retornan periódicamente a su comunidad de origen para recrear su cultura local, para fortalecer sus lazos familiares y comunitarios. La identidad etnocéntrica de los migrantes actúa como un antídoto que impide que sean asimilados rápidamente por el modo de vida y la cultura globalizada de las localidades en donde residen. Así, el turismo nostálgico tiene metas fundamentalmente subjetivas relativas a la identidad y sus efectos en las comunidades de origen son objetivos (económicos). 
Concepto de turismo nostálgico. El turismo nostálgico lo constituye la afluencia de migrantes que retornan periódicamente de sus localidades de residencia a su comunidad de origen por periodos cortos (migrantes circulares). El estudio de este fenómeno social abarca tanto la medición y análisis de los impactos del gasto turístico sobre las actividades económicas como la relación oferta demandademanda de servicios turísticos (Reyes Morales et al., 2005a; Andrade Eekhoff 2004; Grünewald y Pantan 1999). La matriz de contabilidad social y los modelos multisectoriales constituyen los instrumentos apropiados para estudiar los impactos económicos, mientras que las características de la oferta y la demanda, las variaciones estacionales de la afluencia de los turistas nostálgicos se pueden abordar mediante una encuesta administrada durante un año.

Partimos de los resultados de un estudio sobre la migración trasnacional en San Francisco Cajonos, Oaxaca, una comunidad zapoteca en donde se realizó previamente un análisis de los impactos económicos de las remesas familiares (Reyes Morales y Gijón Cruz, 2005). El aporte de este trabajo consiste en presentar, por un lado, resultados de una encuesta dirigida exclusivamente a evaluar las características de la oferta y demanda del turismo nostálgico, la derrama económica; y, por otro, se realiza el análisis de impactos de la derrama económica mediante modelos multisectoriales según Yúnez Naude y Taylor, 1999; Reyes Morales et al., 2005a; Wagner, 1996; Wagner, 1997; Alavalpati y Adamowicz, 2000. Este trabajo es pionero en su género ya que aborda además de los elementos básicos de los estudios del turismo convencional, el análisis de impactos económicos mediante el uso de la matriz de contabilidad social y modelos de multiplicadores. De esta manera, es posible comparar los efectos de la derrama económica del turismo nostálgico con relación a aquellos de las remesas familiares.

\section{EL TURISMO NOSTÁLGICO EN SAN FRANCISCO CAJONOS}

De acuerdo al censo población y migración levantado por el Instituto Tecnológico de Oaxaca en 2005 (Reyes Morales y Gijón Cruz, 2005), esta comunidad mostraba un visible desequilibrio por sexo en su estructura demográfica ${ }^{1}$ debido principalmente al efecto del proceso migratorio. En 1960, la construcción de la primera carretera aceleró el éxodo que inicialmente fue animado por el Programa Bracero. Actualmente, dos tercios de los habitantes de San Francisco Cajonos son nativos y la mitad de la población reside en otras partes de México y los Estados Unidos. A nivel internacional es el estado de California principal lugar de destino y en el territorio nacional la ciudad de Oaxaca, el Distrito Federal y el estado de México. La economía está dominada por la agricultura aunque se observan intentos por diversificar las actividades del sector terciario y aún quedan vestigios de las acti-

\footnotetext{
${ }^{1}$ Existen $11.2 \%$ más mujeres que hombres.
} 
vidades artesanales que hace más de una década eran representativas de San Francisco Cajonos.

Afluencia de los visitantes. Los turistas nostálgicos son migrantes que retornan temporalmente a su comunidad de origen para participar en actividades sociales, familiares y culturales que se desarrollan a lo largo del año. Ellos proceden en su gran mayoría de localidades ubicadas dentro del territorio nacional (86.5\%) pero la presencia de visitantes internacionales no es despreciable (13.5\%). La afluencia de turistas nostálgicos tiene su apogeo en determinadas temporadas del año que coinciden con periodos vacacionales y festividades religiosas. Las características que identifican a este tipo de turismo son: 1) los turistas nostálgicos son nativos de la comunidad de estudio y 2) la principal atracción radica en recrear sus elementos identitarios y en fortalecer sus lazos familiares y comunitarios.

Los visitantes que llegan durante las festividades comunitarias son prácticamente todos turistas nostálgicos acompañados familiares o de amigos nativos de otras comunidades a quienes llamaremos simplemente turistas (véase figura 1). El grupo de visitantes que se desempeñan como comerciantes que viene de las comunidades vecinas es apenas visible a pesar su papel protagónico en la economía de las festividades.

\section{FIGURA 1}

Afluencia de visitantes por tipo en San Francisco Cajonos, Oax., 2006

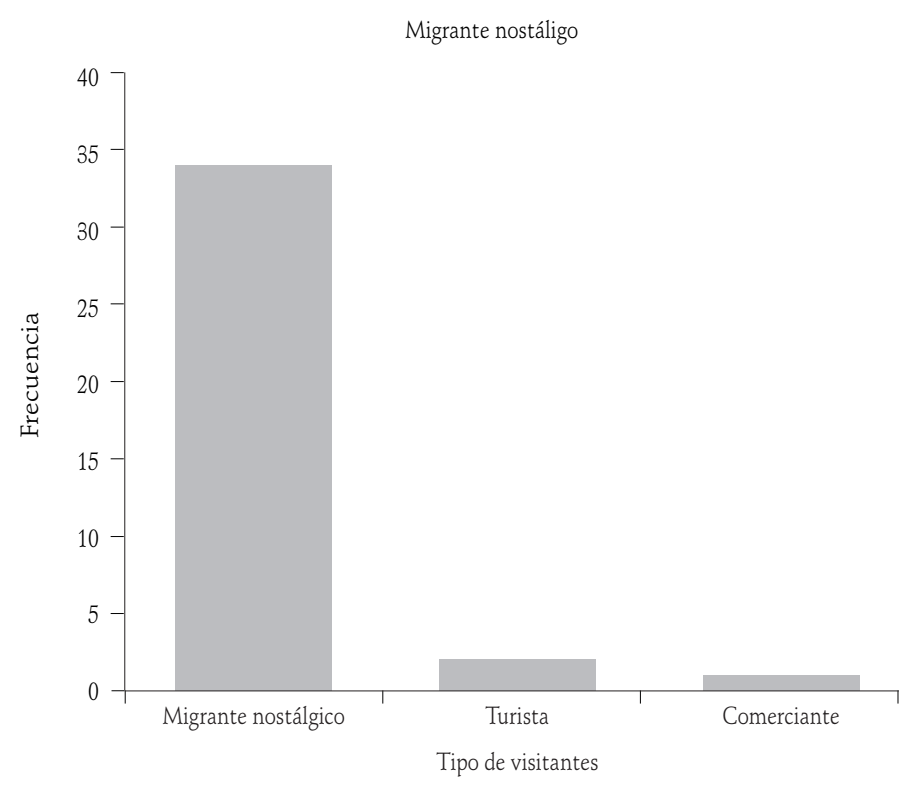

Fuente: Encuesta «Turismo nostálgico» aplicada en San Francisco Cajonos, 2006, Iто.

Estadía. La figura 2 muestra una gran variabilidad en la estadía de los visitantes en San Francisco Cajonos y el promedio anual es de 17.4 días con una desviación estándar de 19.81 días. El lector debe estar consciente que la estadía anual se 
refiere en la mayoría de los casos a una sola visita y en algunos casos incluye la suma de la estadía de varias visitas.

\section{FIGURA 2}

Estadía anual de los turistas nostálgicos en San Francisco Cajonos, Oax., 2006

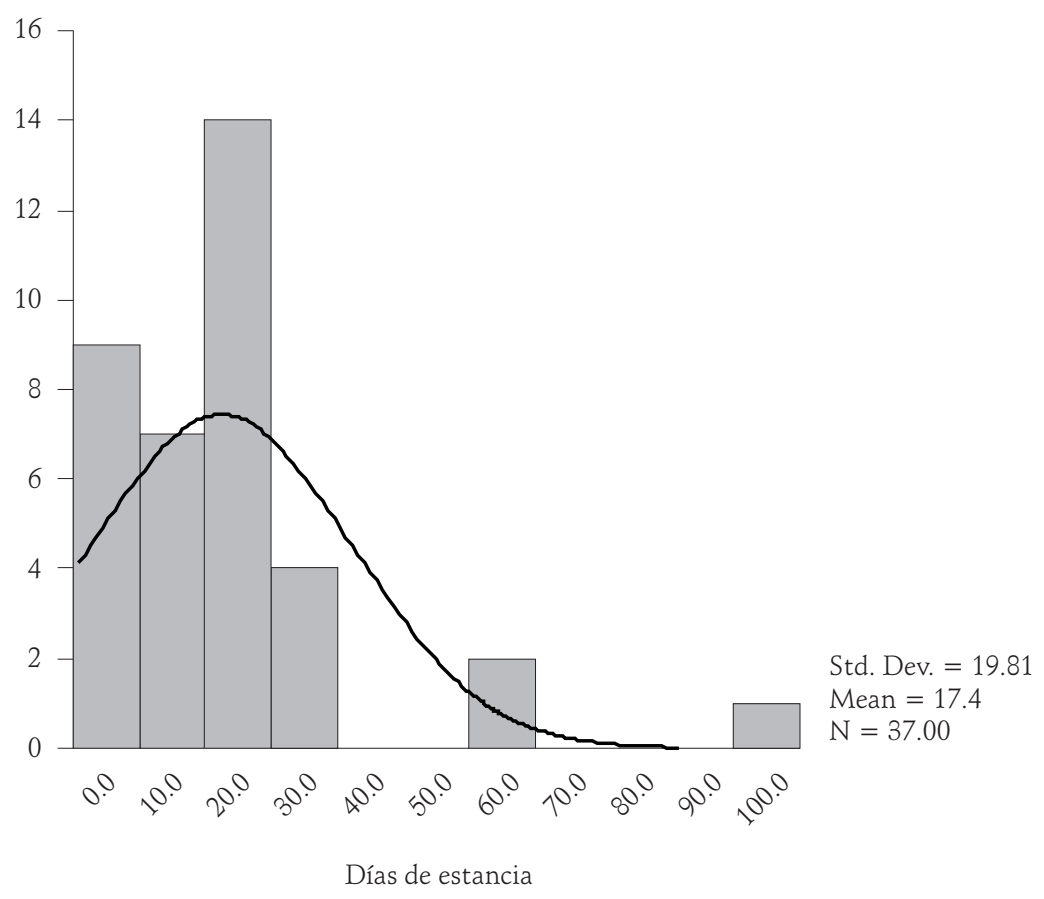

Fuente: Encuesta de «Turismo nostálgico» aplicada en San Francisco Cajonos, 2006, ITO.

Procedencia del visitante. Casi la mitad de los visitantes que llegan a San Francisco Cajonos son de la ciudad de Oaxaca y $10.8 \%$ de otras partes del estado. En total, los visitantes de la entidad hacen $59.4 \%$ de la afluencia total; la ciudad de México aporta $16.2 \%$ de los visitantes al igual que del estado de California en los Estados Unidos; y finalmente, de otras partes de México excluyendo la capital solamente llega 8.1\% de los visitantes (véase cuadro 1). Las ciudades de Oaxaca, México y Los Ángeles contribuyen con $70.2 \%$ de los visitantes que llegan a San Francisco Cajonos y su contribución relativa depende de la distancia y de la presencia de un club de oriundos de San Francisco Cajonos. Así, la ciudad de Oaxaca a menos de 100 kilómetros por una carretera pavimentada que atraviesa picos de la sierra de hasta 3,100 metros de altitud, hace el mayor aporte y la ciudad de México, a varios cientos de kilómetros, aporta un sexto de los visitantes, mientras que la ciudad de Los Ángeles a varios miles de kilómetros hace una contribución pequeña (5.4\%). En realidad, el club de Los Ángeles aglutina prácticamente a todos los visitantes que llegan al estado de California y además capta remesas colectivas para proyectos de desarrollo de San Francisco Cajonos. 
Los visitantes internacionales radican en el estado de California, Estados Unidos y se concentran principalmente en la zona metropolitana de Los Ángeles (Reyes Morales y Gijón Cruz, 2005). Es importante mencionar que estos visitantes tienen una estadía más larga la cual depende, en gran parte, de su estatus migratorio.

\section{CUADRO 1}

Origen del turista nostálgico a San Francisco Cajonos, Oax., 2006

\begin{tabular}{|c|c|c|c|c|c|}
\hline \multicolumn{2}{|c|}{ VISITANTES } & \multicolumn{2}{|c|}{ ORIGEN DEL VISITANTE } & \multirow[b]{2}{*}{ FRECUENCIA } & \multirow[b]{2}{*}{ PORCENTAIE } \\
\hline TIPO & $\%$ & CIUDAD & ESTADO & & \\
\hline \multirow[t]{9}{*}{ Nacional } & \multirow[t]{9}{*}{86.5} & Ciudad de Oaxaca & Oaxaca & 18 & 48.6 \\
\hline & & Ciudad de México & D.F. & 6 & 16.2 \\
\hline & & Comalcalco & Tabasco & 1 & 2.7 \\
\hline & & Etla & Oaxaca & 1 & 2.7 \\
\hline & & Naucalpan & México & 1 & 2.7 \\
\hline & & Puebla & Puebla & 1 & 2.7 \\
\hline & & San Andres Yaa & Oaxaca & 1 & 2.7 \\
\hline & & San Pablo Yaganiza & Oaxaca & 1 & 2.7 \\
\hline & & Santo Domingo Xagacía & Oaxaca & 1 & 2.7 \\
\hline \multirow{6}{*}{$\begin{array}{l}\text { Internacional } \\
\text { (Estados Unidos) }\end{array}$} & \multirow[t]{5}{*}{13.5} & Los Ángeles & \multirow{5}{*}{ California } & 2 & 5.4 \\
\hline & & Rosemead & & 1 & 2.7 \\
\hline & & Sacramento & & 1 & 2.7 \\
\hline & & Tracy & & 1 & 2.7 \\
\hline & & Van Nuys & & 1 & 2.7 \\
\hline & & Total & & 37 & 100.0 \\
\hline
\end{tabular}

Fuente: Encuesta «Turismo nostálgico» aplicada en San Francisco Cajonos, 2006, ITO.

Características de los visitantes y demanda de servicios. Existe equidad de género entre los turistas nostálgicos nacionales. En cambio, entre visitantes internacionales la afluencia se compone de tres quintos de hombres y dos quintos de mujeres. Al parecer, el hospedaje no representa problema para los visitantes, porque la mayoría de ellos cuenta con alojamiento asegurado. El hospedaje lo proporciona la familia en la mayoría de los casos (54\%) y 27\% de los turistas nostálgicos tiene casa propia (véase cuadro 2). Sin embargo, frecuentemente los turistas nostálgicos van acompañados por otros miembros de su familia (78.4\%) o de amigos (5.4\%). En ocasiones, se enfrenta escasez de habitaciones para albergar a los acompañantes. Para cubrir estas necesidades de alojamiento se requiere la implementación de un hostal u hotel que tenga los servicios básicos para los turistas. Una solución viable podría ser arrendar casas de los habitantes que se encuentran ausentes (migrantes) y de esta forma se podría mejorar la oferta de alojamiento.

Como se ha mencionado anteriormente, la visita de los turistas nostálgicos coincide principalmente con fiestas religiosas y las vacaciones de diciembre (figura 3). Las fiestas principales son: «El carnaval», la del santo patrono San Francisco 
CUADRO 2

Hospedaje utilizado por los turistas nostálgicos en San Francisco Cajonos, Oax., 2006

\begin{tabular}{|l|c|c|}
\hline \multicolumn{1}{|c|}{ HOSPEDAJE } & FRECUENCIA & PORCENTAE \\
\hline Con otros familiares & 14 & 37.8 \\
\hline Con sus padres & 10 & 27.0 \\
\hline En su propia casa & 10 & 27.0 \\
\hline $\begin{array}{l}\text { No se hospedan en San Francisco } \\
\text { Cajonos porque viven en comunidades } \\
\text { vecinas. }\end{array}$ & 2 & 5.4 \\
\hline Con amigos & 1 & 2.7 \\
\hline Total & 37 & 100.0 \\
\hline
\end{tabular}

Fuente: Encuesta «Turismo nostálgico» aplicada en San Francisco Cajonos, 2006, Iто.

de Asís y la reciente veneración a los «Santos Fiscales» también llamados Mártires de Cajonos. Estas fiestas constituyen, junto con la familia, los principales atractivos de San Francisco para los turistas nostálgicos. Por lo tanto, los elementos del paquete turístico son: 1) asistir las fiestas de la comunidad; 2) convivir con la familia; y 3) enseñar a los hijos y nietos las tradiciones ancestrales. En las actuales condiciones los servicios (venta de alimentos y de artesanías) constituyen un complemento ya que el alojamiento está asegurado.

\section{FIGURA 3}

Festividades de mayor influencia a San Francisco Cajonos, Oax., 2006

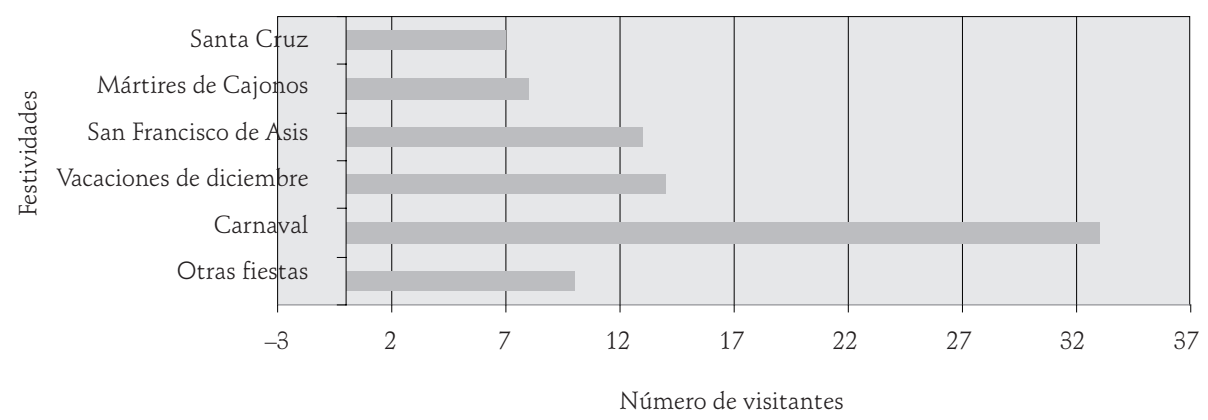

Fuente: Encuesta «Turismo nostálgico» aplicada en San Francisco Cajonos, 2006, ITO.

El comportamiento de la demanda de servicios turísticos en San Francisco Cajonos se refleja en la afluencia de turistas nostálgicos y presenta una estacionalidad bien definida que está sujeta -como el turismo en México- al comportamiento de la economía nacional y mundial. La estadía promedio anual es de 17.4 días muy superior a la estatal (1.84 días) y a la nacional (1.71) según información proporcionada por SECTUR (2005). Aunque el estatus migratorio es una restricción importante para los turistas nostálgicos, el sentido de pertenencia hacia su comunidad de origen elimina muchas veces esta restricción. Los migrantes se arriesgan 
a salir del país receptor aunque tengan que pagar más de 2,000 dólares a un coyote para reingresar. ${ }^{2}$

Una vez que los turistas nostálgicos arriban a la comunidad de origen, existen tres variables importantes a considerar que aseguran una estancia satisfactoria: las necesidades del visitante, sus deseos y el beneficio que obtiene (Grünewald y Pantan et al., 1999). La elección del lugar para pasar las vacaciones se puede evaluar mediante estas variables que tienen una escala nominal. El deseo de visitar el lugar de nacimiento, la familia, de participar en las fiestas del pueblo, conforman un cúmulo de necesidades para los turistas nostálgicos quienes ahorran durante meses o años para realizar el viaje al terruño. Los resultados de la encuesta aplicada en 2006 en San Francisco Cajonos durante el Carnaval (véase cuadro 3) muestran que visitar a la familia y descansar tienen el mismo peso; asistir a las fiestas del pueblo y conservar tradiciones tienen un menor peso. Sin embargo, estos motivos declarados por lo turistas nostálgicos no son excluyentes entre sí sino más bien complementarios porque el hecho de visitar a la familia permite realizar las demás actividades en forma simultánea o escalonada.

\section{CUADRO 3}

Motivos de los turistas nostálgicos para visitar San Francisco Cajonos, Oax., 2006

\begin{tabular}{|l|c|c|}
\hline \multicolumn{1}{|c|}{ MOTIVO DE VISITA } & FRECUENCIA & PORCENTAJE \\
\hline Visitar a la familia & 14 & 37.8 \\
\hline Descansar & 14 & 37.8 \\
\hline Asistir a las fiestas del pueblo & 5 & 13.5 \\
\hline Conservar sus costumbres y tradiciones & 3 & 8.1 \\
\hline Hacer negocio & 1 & 2.7 \\
\hline Total & 37 & 100.0 \\
\hline
\end{tabular}

Fuente: Encuesta «Turismo nostálgico» aplicada en San Francisco Cajonos, 2006, ITO.

El desarrollo de ciertos servicios en San Francisco Cajonos mejoraría considerablemente la oferta turística local aportando beneficios adicionales al visitante. Estos servicios llamarían la atención de un mayor número de turistas nostálgicos y sobre todo de sus acompañantes quienes no tienen el arraigo con las tradiciones y fiestas locales. Al respecto, los turistas nostálgicos respondieron a la pregunta sobre la creación de servicios turísticos considerando nueve opciones de respuesta cerradas y una abierta en el siguiente orden (véase figura 4): 1) un hotel, 2) venta de artesanías, 3) venta de recuerdos, 4) restaurantes, 5) oficina de información turística, 6) guías de turista y 7) Internet. Las tres primeras acciones propuestas por los visitantes pueden formar un proyecto coherente que diversifique el actual mosaico de opciones ofreciendo alternativas de entretenimiento y diver-

2 El costo para cruzar la frontera es actualmente de 2,000 dólares para niños y 3,000 dólares para adultos. 
sión. La creación de un hotel o casa de huéspedes ofrecería alojamiento para los acompañantes de los turistas nostálgicos, mientras una tienda o un mercado de artesanías ofrecerían tanto artesanías locales como regionales que los turistas ya se llevan como recuerdos de su estancia en la comunidad. Asegurando el alojamiento, seguramente atraerá un mayor número de turistas que buscan esparcimiento y descanso durante las fiestas de la comunidad y diciembre. En consecuencia, los turistas convencionales contarían además de las fiestas con los servicios de cualquier destino turístico como son: restaurantes, venta de recuerdos y alojamiento. De esta manera, seguramente incrementará la derrama económica sobre las actividades productivas locales. Visto del lado de los dueños de restaurantes y hoteles, se crearían las condiciones para que los negocios sobrevivan más allá de los periodos de mayor afluencia. Las autoridades municipales tendrían que apuntalar el turismo creando una oficina de información y el servicio de guías para los visitantes. Al respecto, existen experiencias exitosas en muchos municipios rurales del estado de Oaxaca que pueden ser aprovechadas.

FIGURA 4

Demanda de servicios en San Francisco Cajonos, Oax., 2006

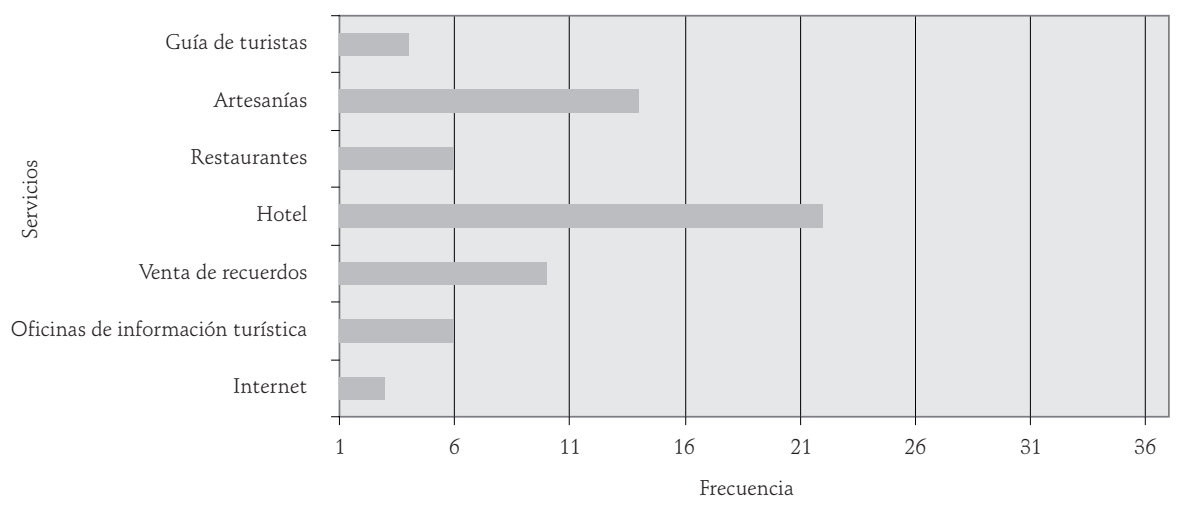

Fuente: Encuesta «Turismo nostálgico» aplicada en San Francisco Cajonos, 2006, ITO.

Asimismo, existe demanda en menor grado de otros servicios que los visitantes consideraron importantes. Éstos se refieren a la necesidad de resolver el problema del abastecimiento de agua potable que constituye un cuello de botella durante festividades y el mes diciembre. Alternativamente a los hoteles, otros propusieron la construcción de cabañas ecológicas situadas entre el bosque y la comunidad. Otras demandas adicionales fueron para mejorar la oferta turística local e incrementar la afluencia de visitantes: un mercado en donde la población residente y visitantes puedan adquirir productos de primera necesidad (frutas, verduras, legumbres, carnes); un estacionamiento público; el abastecimiento de medicamentos para la clínica; y una mayor difusión de San Francisco Cajonos como destino turístico. 


\section{RELACIÓN ENTRE TURISMO NOSTÁLGICO Y DESARROLLO LOCAL}

\section{Impactos de la derrama del turismo nostálgico en la economía local}

Se tomó como base la matriz de contabilidad social de esta comunidad elaborada con datos de 2004 (Reyes Morales y Gijón Cruz, 2005). Se estimó la derrama económica anual en \$344,074 mediante la encuesta de turismo nostálgico 2006. ${ }^{3}$ En comercio y servicios los turistas nostálgicos gastaron $\$ 210,745$ en la compra de alimentos y ropa, en las fiestas, vivienda y salud. Asimismo, gastaron $\$ 12,903$ en artesanías y además se consideró una cantidad igual en ahorro físico que se refiere a la vivienda. Es conveniente aclarar al lector que en la teoría económica el gasto en vivienda se considera dos veces porque por un lado constituye un gasto en materiales de construcción que se hace en las tiendas y, por otro, la vivienda construida es un activo (ahorro físico). En suma, la cantidad total que se inyectó a la economía de San Francisco Cajonos mediante la derrama económica del turismo nostálgico fue $\$ 236,551$. Para evaluar los impactos en la economía de San Francisco Cajonos, se realizó una simulación utilizando modelos de multiplicadores de acuerdo con la metodología expuesta por Reyes Morales et al., 2005a. Se utilizó el programa General Algebraic Modeling System (GAMs) para el cálculo de los multiplicadores de gasto con el apoyo de una rutina proporcionada por el Programa de Estudios del Cambio Económico y la Sustentabilidad del Agro Mexicano (PRECESAM). Los resultados de la simulación aparecen en el cuadro 4. La economía medida por el producto interno bruto (PIB) creció 1.5\% con relación al año anterior. La ganadería de traspatio creció 92.7\%; esta actividad incluye la cría y engorda de gallinas, guajolotes, borregos, yuntas, becerros y caballos (véase cuadro 5). Los visitantes incrementan el consumo local de huevos, carne de borrego en barbacoa, así como manufacturas en pequeña escala (pan y mezcal) y artesanía que también se producen en el traspatio. De esta manera, se crea un auge en la producción del traspatio.

El crecimiento de la economía en general y en particular de la ganadería de traspatio se refleja en un aumento en la demanda de mano de obra tanto asalariada como familiar que crecen 1.83 y $1.20 \%$, respectivamente. En San Francisco Cajonos no se requiere llevar los excedentes de producción agrícola, ganadera y de alimentos elaborados al mercado regional con excepción de las artesanías, porque la población y el turismo nostálgico los consumen localmente (comparar ventas locales y regionales, véase cuadro 7). La respuesta de la agricultura de autoconsumo al gasto turístico fue apenas visible (0.76\%) porque en 2004 esta actividad presentaba un valor negativo de la retribución al trabajo familiar. ${ }^{4}$

\footnotetext{
3 Para la estimación también se consideraron los resultados del censo de población y migración 2005 y de la etnoencuesta 2005 (Reyes Morales y Gijón Cruz 2005).

4 Se refiere al ingreso neto (ganancias) de la producción agrícola.
} 


\section{CUADRO 4}

Impactos de las remesas familiares y la derrama del turismo nostálgico en San Francisco Cajonos, 2004-2006

\begin{tabular}{|c|c|c|c|c|c|}
\hline & \multirow{2}{*}{$\begin{array}{l}\text { BASE } \\
(2004)\end{array}$} & \multicolumn{2}{|c|}{ REMESAS (2005) } & \multicolumn{2}{|c|}{$\begin{array}{l}\text { CASTOS EN LA COMUNIDAD } \\
\text { POR TURISMO NOSTÁLGICO } \\
(2006)\end{array}$} \\
\hline & & $\begin{array}{l}\text { DEVALUACIÓN } \\
\text { DEL 20\% } \\
\text { DEL PESO }\end{array}$ & $\begin{array}{c}4.4 \% \text { DE } \\
\text { CRECIMIENTO } \\
\text { DEL PIB DE } \\
\text { ESTADOS UNIDOS }\end{array}$ & ACTIVIDAD & INYECCIÓN \\
\hline \multicolumn{6}{|l|}{ CAMBIO EXÓGENO (Pesos) } \\
\hline $\begin{array}{l}\text { 1) Por remesas a las actividades no } \\
\text { agropecuarias. }\end{array}$ & & 17,178 & & $\begin{array}{l}\text { Comercio } \\
\text { y Servicio }\end{array}$ & 210,745 \\
\hline $\begin{array}{l}\text { 2) Aumento de remesas a las actividades } \\
\text { no agropecuarias. }\end{array}$ & & & 3,780 & $\begin{array}{l}\text { Ahorro } \\
\text { Físico }\end{array}$ & 12,903 \\
\hline $\begin{array}{l}\text { 3) Participación del cambio en el ingreso } \\
\text { de la cuenta. }\end{array}$ & & 1.022 & 0.225 & Artesanías & 12,903 \\
\hline \multicolumn{6}{|c|}{ Cambios en el Ingreso \% } \\
\hline Producto Interno Bruto (PIB) real & $3^{\prime} 776,871$ & 0.442 & 0.097 & & 1.498 \\
\hline \multicolumn{6}{|l|}{ PRODUCCIÓN } \\
\hline 1. Agricultura de autoconsumo & $1^{\prime} 085,207$ & 0.093 & 0.021 & & 0.757 \\
\hline 2. Ganadería de traspatio & 77,475 & -0.058 & -0.013 & & 92.660 \\
\hline 3. Recursos naturales (leña) & 257,428 & 0.150 & 0.033 & & 0.508 \\
\hline 4. Comercio y servicios & 4’095,503 & 0.122 & 0.027 & & 7.649 \\
\hline 5. Producción artesanal & $1^{\prime} 753,853$ & 0.982 & 0.216 & & 0.744 \\
\hline \multicolumn{6}{|l|}{ FACTORES } \\
\hline 1. Tierra & 15,688 & 0.093 & 0.021 & & 0.757 \\
\hline 2. Capital & 148,371 & 0.348 & 0.077 & & 2.304 \\
\hline 3. Trabajo asalariado & 1'521,477 & 0.504 & 0.111 & & 1.832 \\
\hline 4. Trabajo familiar & 2’091,335 & 0.406 & 0.089 & & 1.203 \\
\hline \multicolumn{6}{|l|}{ INSTITUCIONES } \\
\hline 1. Hogares receptores de remesas & 8'508,130 & 0.086 & 0.019 & & 0.295 \\
\hline 2. Hogares no receptores de remesas & 6'160,883 & 0.209 & 0.046 & & 0.702 \\
\hline 3. Organización comunitaria & 100,000 & 0.000 & 0.000 & & 0.000 \\
\hline 4. Gobierno & 411,346 & 0.115 & 0.025 & & 2.297 \\
\hline \multicolumn{6}{|l|}{ AHORRO-INVERSIÓN } \\
\hline 1. Capital físico & $-42,590$ & 0.190 & 0.042 & & -0.297 \\
\hline 2. Capital humano & 926,615 & 0.112 & 0.025 & & 0.000 \\
\hline \multicolumn{6}{|l|}{ RELACIONES CON EL EXTERIOR } \\
\hline 1. Resto de la región & $8^{\prime} 077,240$ & 0.170 & 0.037 & & 2.688 \\
\hline 2. Resto de México & 5775,340 & 0.047 & 0.010 & & 0.158 \\
\hline 3. Resto del mundo & $5^{\prime} 281,433$ & 0.005 & 0.001 & & 0.016 \\
\hline
\end{tabular}

Fuente: «Impacto de las remesas»: Reyes Morales, Rafael G. y Alicia Sylvia Gijón Cruz, 2005. Economía, migración trasnacional, cultura y religión en San Francisco Cajonos, Instituto Tecnológico de Oaxaca, México; Impacto de la derrama del turismo nostálgico: Encuesta Turismo nostálgico aplicada en San Francisco Cajonos en 2006 por el rTo y cálculo de los multiplicadores contables mediante el programa GAMs realizado por Andrés Cuauhtémoc Cruz Contreras.

La agricultura de autoconsumo proporciona alimentos a las familias productoras y a otras familias a través de regalos, insumos para la ganadería de traspatio 
(rastrojo y maíz en grano de baja calidad). En realidad, sí se producen excedentes que no salen al mercado y constituyen insumos para ganadería de traspatio.

Otras actividades y cuentas que tienen respuestas visibles a la derrama del turismo nostálgico fueron: resto de la región $(2.69 \%)$, capital $(2.30 \%)$, gobierno $(2.30 \%)$ y trabajo asalariado (1.83\%). El incremento de la cuenta de capital está asociado a la compra de activos tales como herramientas, equipo, maquinaria y vehículos utilizados en negocios y en la producción en general. El crecimiento del trabajo asalariado indica que los hogares liberan mano de obra respondiendo a la demanda del mercado laboral local. Las actividades que requieren mano de obra son: agricultura de autoconsumo, ganadería de traspatio, productos de origen animal (carne si procesar), manufacturas en pequeña escala (alimentos y bebidas), la construcción y recolección de leña. Durante las fiestas la demanda de mano de obra se incrementa. Por el contrario, el rubro de gobierno implica la salida de dinero de la comunidad vía impuestos como resultado del aumento de la actividad económica total. De la misma manera, la cuenta resto de la región proporciona información del dinero que sale de la comunidad hacia la región para la compra de insumos para la producción, el comercio, los servicios y los gastos de los hijos que asisten a escuelas foráneas. Estas fugas de dinero van disminuyendo conforme pasamos a los ámbitos nacional (resto de México) e internacional (resto del mundo).

Ahora analicemos la respuesta en las actividades en donde se hizo la inyección de dinero procedente de la derrama económica a través de la simulación. Comercio y servicios que recibió $89.2 \%$ de la inyección solamente creció $7.65 \%$ a pesar del ser el sector más grande de la economía. La explicación está en la estacionalidad del turismo nostálgico que no genera una demanda de bienes y servicios sostenida a lo largo del año. Por lo tanto, los dueños de los negocios realizan sus mayores inversiones durante los periodos de afluencia de los turistas nostálgicos. El resto del año sus clientes se reducen a una población de solamente 261 habitantes de bajo poder adquisitivo. Esta situación contrasta con la de Teotitlán del Valle y Villa de Mitla cuya afluencia fluctúa durante el año, pero no desaparece completamente. La cercanía a la ciudad de Oaxaca -un importante destino turístico nacional fuera las costas- permite atraer a los visitantes de esta ciudad al mercado de artesanías y al museo de sitio de estas dos localidades.

La producción artesanal y el ahorro físico recibieron 7.65\% de la inyección cada uno y los resultados fueron muy exiguos. La primera actividad creció $0.744 \%$ mientras que la segunda tuvo un decrecimiento de $-0.297 \%$. La producción artesanal muestra muy baja capacidad de respuesta a un incremento en la demanda de las artesanías en las condiciones actuales. En particular, la producción de redes y hamacas es una actividad en decadencia desde hace varias décadas. El proceso de producción incluía: la extracción de ixtle de maguey y la elaboración de artículos a mano para la agricultura (redes) y para descansar (hamacas). Sin embargo, 


\section{CUADRO 5}

Producción agrícola, ganadera y manufacturera en el traspatio, y agrícola de autoconsumo en San Francisco Cajonos, 2004.

(Valores muestrales, en pesos)

\begin{tabular}{|c|c|c|c|c|c|}
\hline & \multicolumn{3}{|c|}{ PRODUCCIÓN EN EL TRASPATIO } & \multirow[b]{2}{*}{$\begin{array}{c}\text { EXTRACCIÓN } \\
\text { DE LEÑA }\end{array}$} & \multirow[b]{2}{*}{$\begin{array}{l}\text { AGRICULTURA DE } \\
\text { AUTOCONSUMO }\end{array}$} \\
\hline & AGRICULTURA & GANADERÍA & $\begin{array}{l}\text { PRODUCCIÓN DE } \\
\text { ORIGEN ANIMALY } \\
\text { MANUFACTURAS }\end{array}$ & & \\
\hline Valor bruto de la producción & $\$ 17,283$ & $\$-39,155$ & $\$ 306,398$ & $\$ 43,000$ & $\$ 62,897$ \\
\hline Ventas locales & $\$ 3,783$ & $\$ 22,740$ & $\$ 294,448$ & 0 & $\$ 2,050$ \\
\hline Ventas regionales & 0 & 0 & $\$ 8,050$ & 0 & 0 \\
\hline Consumo propio (humano) & $\$ 6,758$ & $\$ 11,520$ & $\$ 3,000$ & $\$ 42,400$ & $\$ 5,6971$ \\
\hline Consumo propio (transformación) & $\$ 5,425$ & 0 & 0 & 0 & $\$ 754$ \\
\hline Valor de la producción regalada & $\$ 1,335$ & $\$ 680$ & $\$ 1,000$ & 0 & $\$ 3,122$ \\
\hline Salarios locales & $\$ 600$ & $\$ 2,750$ & $\$ 150$ & $\$ 1,400$ & $\$ 24,720$ \\
\hline Salarios regionales & 0 & 0 & 0 & 0 & $\$ 2,080$ \\
\hline Retribución al trabajo familiar & $\$ 16,474$ & $\$-13,172$ & $\$ 206,516$ & $\$ 35,195$ & $\$-3,313$ \\
\hline Insumos regionales & $\$ 126$ & $\$ 13,704$ & $\$ 76,476$ & 0 & $\$ 1,420$ \\
\hline Insumos propios & 0 & $\$ 4,747$ & 0 & 0 & $\$ 3,186$ \\
\hline Pérdidas & - & $\$ 13,390$ & - & - & - \\
\hline Productos & $\begin{array}{l}\text { Maíz } \\
\text { Frijol } \\
\text { Calabaza } \\
\text { Garbanzo } \\
\text { Hortalizas } \\
\text { Café } \\
\text { Frutales }\end{array}$ & $\begin{array}{l}\text { Gallinas } \\
\text { Guajolotes } \\
\text { Borregos } \\
\text { Becerros } \\
\text { Toros y va- } \\
\text { cas } \\
\text { Caballos }\end{array}$ & $\begin{array}{l}\text { Huevo } \\
\text { Barbacoa } \\
\text { Mezcal } \\
\text { Tortillas } \\
\text { Artesanía } \\
\text { textiles } \\
\text { Prendas } \\
\text { bordadas } \\
\text { Artículos de } \\
\text { madera } \\
\text { Estructuras } \\
\text { metálicas }\end{array}$ & Leña & $\begin{array}{l}\text { Maíz } \\
\text { Frijol } \\
\text { Calabaza }\end{array}$ \\
\hline
\end{tabular}

a Las manufacturas incluyen a las artesanías (textiles y prendas bordas).

Fuente: Matriz de contabilidad social muestral de San Francisco Cajonos 2004, iтo 2005; cálculos propios.

los artesanos no pudieron adaptarse a la sustitución del ixtle por fibras sintéticas y encontraron en la migración la solución al desempleo. Al emigrar los artesanos se fue perdiendo el conocimiento y la experiencia acumulados en esta actividad. En cambio, la producción de barbacoa de borrego, tortilla, pan y mezcal han tenido mayor capacidad de respuesta a la demanda de la afluencia turística. En este sentido, una tienda especializada, o un mercado de artesanías, impulsaría la venta de productos artesanales siempre y cuando al mismo tiempo se realice una campaña de promoción turística.

El desahorro en capital físico tiene una interpretación intrínseca al modelo de multiplicadores el cual por ser de tipo lineal proyecta una tendencia en el senti- 
do que le indica la matriz de contabilidad social. La economía local presentaba un desahorro en capital físico en 2004; es decir, el saldo entre gasto en la construcción obtenido de los ahorros disponibles y la venta de viviendas y terrenos urbanos fue negativo. Esta situación se explica en parte por la ausencia de un mercado de bienes raíces en las localidades rurales lo cual se acentúa aún más en comunidades indígenas. El cambio de propietario de casas y terrenos normalmente ocurre por herencia de padres a hijos. Normalmente no se permite que gente de fuera compre terrenos agrícolas, terrenos urbanos o casas a menos que se integren a la comunidad a través del sistema de cargos. Otra manera de adquirir terrenos agrícolas para los ciudadanos varones es solicitar una parcela a las autoridades agrarias locales siempre y cuando los solicitantes hayan cumplido con los cargos asignados por la asamblea comunitaria. Las viviendas nuevas o las mejoras a las viviendas actuales se financian en la mayoría de los casos con remesas familiares. Sin embargo, los flujos de remesas familiares para la construcción no ocurren todos los años ni es común a todas las familias. En síntesis, la derrama del turismo nostálgico redujo el desahorro en capital físico a un valor cercano a cero porque el gasto en vivienda creció a tal grado que casi compensó el desahorro estructural reportado en 2004.

Finalmente, es necesario subrayar los efectos en las cuentas que no tuvieron respuesta a la inyección que son: la organización comunitaria y el ahorro en capital humano. La organización comunitaria aunque tiene que ver con la organización y financiamiento de las fiestas, no responde a incrementos en el turismo nostálgico ni al aumento de las remesas familiares. La organización comunitaria responde al flujo de remesas colectivas que recibe de los clubes en las ciudades de Los Ángeles, Oaxaca y México. Los turistas nostálgicos no pagan por asistir a las fiestas y realizan aportaciones de dinero a su club en la localidad donde residen. Asimismo, la comunidad realiza aportaciones voluntarias en especie para la fiesta y el mismo Ayuntamiento Municipal contribuye con fondos. Por esta razón, la matriz de contabilidad social no registra las relaciones entre la organización comunitaria y los turistas. Tampoco se detectó relación entre la derrama turística y el ahorro en capital humano (inversión en educación) que sí es sensible a un cambio en el flujo de remesas familiares. Durante su visita los migrantes no asignan dinero a la educación de sus hijos y son las remesas familiares las que financian este rubro del gasto del hogar. El migrante cuando visita su comunidad de origen es técnicamente turista nostálgico y cuando se encuentra ausente envía remesas para el sostenimiento y el mejoramiento del nivel de vida de su familia.

\section{Derrama turística versus remesas familiares}

Se analizaron los resultados de dos simulaciones que estiman el impacto de las remesas familiares en la estructura económica de San Francisco Cajonos en 
2006. La primera se basa en una posible devaluación del peso en un $20 \%$ que induce un aumento en el valor dólar y, por lo tanto, un incremento en el valor de las remesas en la misma proporción. La segunda considera un aumento en las remesas familiares proporcional a la tasa de crecimiento de la economía norteamericana estimada para 2006 (4.4\%). En el caso de la devaluación se inyecta $\$ 17,178$ a la producción artesanal y el segundo caso se inyecta $\$ 3,780$ a esta misma actividad. Las dos simulaciones anteriores produjeron una tasa de crecimiento inferior a la producida por la simulación de la derrama económica del turismo nostálgico. Asimismo, el turismo nostálgico produjo impactos en la estructura económica de San Francisco Cajonos que contrastan con los de la devaluación del peso y crecimiento de la economía norteamericana.

La derrama económica del turismo nostálgico produce los mayores impactos en las actividades económicas sobre todo en la ganadería de traspatio y en menor grado en el comercio y los servicios. Por esta razón, los factores de la producción crecen significativamente y principalmente el capital. Sin embargo, el crecimiento de las actividades primarias y terciarias se refleja al mismo tiempo en un aumento en las fugas de dinero hacia el resto de la región y a través de la captación de impuestos por parte del gobierno.

Las dos simulaciones de remesas familiares benefician más a las familias que a las actividades económicas con la excepción de la producción artesanal. Es decir, las remesas además de financiar el consumo de las familias de los migrantes fortalecen la producción artesanal. Los hogares que no reciben remesas se benefician a través de los salarios pagados por los hogares con remesas. Asimismo, el ingreso monetario obtenido por la venta de mano de obra permite incrementar el ahorro físico (vivienda) y la inversión en educación (capital humano). Finalmente, el crecimiento de la economía local debido al aumento de las remesas familiares produce mayores fugas de dinero hacia el resto de la región que la derrama del turismo nostálgico. Las crecientes fugas de dinero en la economía de San Francisco Cajonos se deben a dos razones principales. La economía está incompleta ya que carece de bancos o cajas de ahorro que proporcionen servicios financieros y permitan reciclar los flujos de dinero que entran a la comunidad a través de remesas, derrama económica del turismo y subsidios de gobierno (Goldring, 2004; Reyes Morales et al., 2005b). En estas condiciones, la mayor parte del dinero que llega a la comunidad se fuga hacia el mercado regional en donde se adquieren bienes y servicios tanto para los hogares como para los negocios. La segunda razón se refiere a la incapacidad de las actividades productivas locales para satisfacer la demanda de bienes y servicios de la población, así como para producir excedentes para el mercado regional que compensen las fugas de dinero.

Varias de las actividades productivas son de autoconsumo (agricultura, ganadería de traspatio, extracción de leña), mientras que comercio y servicios están orientados al mercado local y la producción artesanal llega hasta el mercado regional. El intercambio con la región produce un déficit que se cubre con remesas 
familiares y subsidios del gobierno. Es decir, los flujos de dinero que entran a la comunidad de estudio se fugan hacia el resto de la región y, por consiguiente, tienen un impacto muy limitado en el desarrollo local.

\section{CONCLUSIONES Y PROPUESTAS}

\section{Lecciones del turismo nostálgico desde San Francisco Cajonos}

La afluencia de visitantes a San Francisco Cajonos está formada principalmente por personas nativas quienes emigraron con el fin de mejorar su calidad de vida y que regresan temporalmente para visitar a sus familiares, descansar y disfrutar de las fiestas. Ellos visitan su comunidad de origen motivados por la necesidad de mantener vínculos familiares, comunitarios y culturales, ya que de acuerdo con Hirai (2002), ellos experimentan un sentimiento de pérdida de su hogar y pasado. Los lazos afectivos con la familia y la comunidad de origen son parte de los valores aprendidos en el seno familiar y que los migrantes circulares (turistas nostálgicos) pretenden no sólo conservar sino sobre todo realizan esfuerzos por trasmitirlos a sus hijos y nietos.

El turismo nostálgico puede durar mientras haya migrantes y sus hijos y nietos mantengan lazos con la comunidad de origen de sus padres y abuelos. En Europa se puede observar que muchos turistas visitan los pueblos de sus ancestros que salieron hace varios siglos y buscan vestigios de su cultura heredada. Algo similar ocurre con los turistas europeos y norteamericanos quienes tratan de encontrar en Oaxaca de manera consciente o inconsciente en las artesanías, los bailes autóctonos y la gastronomía tradicional sus culturas rurales que se erosionaron durante los procesos de industrialización, urbanización y globalización del siglo xx. Es decir, el turismo nostálgico también tiene potencial para inducir la afluencia del turismo cultural que en el futuro deberá adquirir un peso importante para compensar una lenta disminución de turistas nostálgicos. La migración puede reducirse si las actividades artesanales locales se fortalecen mediante un incremento del turismo. Al respecto, en la región Valles Centrales de Oaxaca, Teotitlán del Valle y Villa de Mitla localidades con fuerte vocación turística son excelentes ejemplos. Otros factores que pueden causar la disminución de la migración en San Francisco Cajonos podrían ser un estancamiento de la economía norteamericana y un endurecimiento de las políticas migratorias para reducir la inmigración. San Francisco Cajonos cuenta con tradición artesanal, una zona arqueológica, bellezas naturales, un museo de sitio, una banda de música, folclor, un taller de artes gráficas y gastronomía. Estos atributos rivalizan con los de las dos comunidades mencionadas arriba y podrían jugar un papel estratégico entre los pueblos del distrito de Villa Alta en la región Sierra Norte, porque se encuentra en el cruce de las carreteras que comunican a la gran mayoría de las comunidades de este distrito. 
A nivel internacional, un porcentaje importante de inmigrantes visita sus países de origen como turistas nostálgicos; sin embargo, ningún gobierno tiene una política turística destinada al aprovechamiento de su propia diáspora lo cual representa una pérdida de oportunidades económicas para las comunidades de origen (Orozco, 2003; Candor, 2005; Reyes Morales et al., 2004).

Las remesas familiares benefician más a las familias que a las actividades económicas. Incluso los hogares que no reciben remesas se benefician a través de los salarios pagados por los hogares con remesas y, de esta manera, pueden incrementar su liquidez, el ahorro físico (vivienda) y la inversión en educación (capital humano). Finalmente, el crecimiento de la economía local inducido por un aumento de las remesas incrementa, al mismo tiempo, la dependencia del exterior. Esto se debe a que la economía está incompleta ya que carece de bancos o cajas de ahorro que reciclen los flujos de dinero que entran a la comunidad. Asimismo, las economías rurales generalmente son poco diversificadas y producen escasos excedentes -o son de autoconsumo-, ya sea para poder satisfacer la demanda de bienes y servicios de su población o ya sea para compensar el déficit con el exterior. En cambio, el comercio y los servicios están orientados al mercado local mientras que la producción artesanal llega hasta el mercado regional. El intercambio con la región produce déficit que se cubre con remesas familiares y subsidios del gobierno. Es decir, los flujos de dinero que entran a la comunidad de estudio se fugan hacia el resto de la región.

\section{¿Remesas familiares o derrama económica del turismo nostálgico?}

Las remesas familiares se utilizan para elevar el consumo y nivel de vida de los hogares receptores pero también tienen un impacto positivo en la producción de artesanías. La derrama económica del turismo nostálgico beneficia principalmente a las actividades económicas y en particular la ganadería de traspatio, el comercio y los servicios. Por esta razón, se observa un incremento en los factores de la producción pero sobretodo en la cuenta de capital y trabajo asalariado. El modelo de multiplicadores estima una expansión del gobierno debido a que el auge estacional de la derrama económica induce fugas de dinero hacia e exterior vía impuestos. Las fugas también crecen hacia el «resto de la región» que abastece a los hogares de bienes y servicios. Esto ocurre tanto en el caso de las remesas familiares como en el turismo nostálgico porque la economía de San Francisco Cajonos como el resto de las comunidades rurales de México carece de servicios financieros (bancos, cajas de ahorro, microbancos, etc.). Esta falla estructural de las economías rurales esta presente desde países en vías de desarrollo hasta en la mayoría de las nuevas economías industrializadas. En este contexto, los beneficios del turismo nostálgico y de las remesas familiares tienen un efecto limitado en el desarrollo local, ya que las fugas de dinero benefician más a los negocios de los mercados regionales (Reyes Morales et al., 2005b). 
La propuesta de crear un desarrollo turístico comunitario para retener más tiempo al turismo nostálgico y así incrementar su gasto, permitiría aumentar los beneficios localmente. Se propone la creación de un mercado de artesanías, hoteles o casas de huéspedes y restaurantes. Este paquete pretende extender la derrama del turismo nostálgico más allá de los periodos de mayor afluencia y además atraer visitantes regionales, nacionales e internacionales procedentes de la ciudad de Oaxaca.

Podemos concluir que la derrama del turismo nostálgico activa temporalmente la economía de San Francisco Cajonos, mientras que las remesas sostienen el nivel de las familias. Aunque la estadía es considerablemente mayor que en el estado de Oaxaca y la República Mexicana, no es suficiente para sostener un proceso de desarrollo local. Esto se debe en parte a la ausencia de servicios financieros que reciclen principalmente el flujo de dinero procedente del turismo y las remesas; y en parte a que hasta ahora no se han aprovechado las ventajas comparativas de San Francisco Cajonos para promoverlo como un destino para el turismo rural. Asimismo, el lector debe notar que la encuesta rápida aplicada sobre la oferta y demanda de los servicios turísticos y la derrama económica del turismo nostálgico permitió obtener información confiable y precisa. La matriz de contabilidad social constituye una herramienta muy útil para medir los impactos de la derrama del turismo nostálgico en la estructura de la economía local mediante el uso de modelos de multiplicadores al igual que en el caso de las remesas. Así, fue posible comparar los impactos de la migración vía remesas familiares versus derrama económica. Y seguramente el hallazgo más importante fue determinar que el turismo nostálgico fortalece las actividades económicas y las remesas familiares el consumo y el bienestar de los hogares.

\section{REFERENCIAS}

Alavalpati, Janaki R.R. and Wiktor L. Adamowicz (2000), «Tourism impact modelling for resource extraction regions", Annals of Tourism Research, vol. 27, núm. 1, pp. 188-202.

AndRADE-EEKHOfF, Katharine E. (2004), Ante retos locales, acciones globales: La migración laboral $y$ los nuevos retos para la formulación de políticas en un mundo transnacional, Fundación Canadiense para las Américas (Focal), FPP-04-7, octubre.

CANDOR, Eric (2005), «Remesas y desarrollo: Lecciones desde la comunidad transnacional garífona», Intercambios, Año 5, núm. 53, agosto.

DeLGADo Wise, Raúl (2004), «Globalización y migración laboral internacional. Reflexiones en torno al caso México», en Raúl Delgado Wise y Margarita Favela (coordinadores), Nuevas tendencias y desafios de la migración internacional México-Estados Unidos, México, Miguel Ángel Porrúa, pp. 13-33.

Gartner, William C. y David W. (2000), Trends in Outdoor Recreation, Leisure and Tourism, Lime, CABI Publishing, U.K.

Goldring, Luin (2004), «Remesas y microbancos», Migración y Desarrollo, Red Internacional de Migración y Desarrollo, núm. 3, pp. 92-98. 
GRÜNEWALd, Luis, Liliana Pantan et al. (1999), Turismo para todos, pautas de calidad y atención a personas con capacidades restringidas, Secretaria de Turismo de la Nación, Buenos Aires, Universidad del Salvador.

Guarnizo, Luis, Alejandro Portes y Patricia Landolt (2003), La globalización desde abajo: Transnacionalismo inmigrante y desarrollo. La experiencia de Estados Unidos y América Latina, Facultad Latinoamericana de Ciencias Sociales, Secretaria General, ISBN: 970701-365-6.

HIRAI, Shinji (2002), Viajes al terruño imaginario: El Estado post-nacional y el turismo diaspórico mexicanos, México, Departamento de Antropología, Universidad Autonoma Metropolitana, Unidad Iztapalapa.

LevitT, Peggy y Nina Glick Schiller (2004), «Perspectivas internacionales sobre migración: Conceptualizar la simultaneidad», Migración y Desarrollo, Red Internacional de Migración y Desarrollo, núm. 3, pp. 60-91.

Lozano Ascensio, Fernando (2003), "Discurso oficial, remesas y desarrollo en México», Migración y Desarrollo, Red Internacional de Migración y Desarrollo, núm. 1: pp. 23-31.

Moctezuma, Miguel (2005), Morfología y desarrollo de las asociaciones de mexicanos en Estados Unidos, un sujeto social y político extraterritorial, Working paper, Universidad de Zacatecas, 30/11/2005.

Orozco, Manuel, (2005), «Trasnacionalismo y desarrollo: Tendencias y oportunidades en América Latina», Foreing Affair, vol. 5, núm. 3.

Manuel (2003), El futuro de América Central y el Caribe: Opciones de políticas, Fundación Canadiense para las Américas (Focal), FPP-03-06, marzo.

Portes, Alejandro (2005), «Convergencias teóricas y evidencias empíricas en el estudio del transnacionalismo de los migrantes», Migración y Desarrollo, Red Internacional de Desarrollo, primer semestre, núm. 4, pp. 2-19.

Reyes Morales, Rafael G. y Alicia Sylvia Gijón Cruz (coordinadores) (2005), Economía, migración transnacional, cultura y religión en San Francisco Cajonos, México, Instituto Tecnológico de Oaxaca, IsBn: 970-9916-02-5.

, Alicia Sylvia Gijón Cruz, Antonio Yúnez Naude y Raúl Hinojosa Ojeda (2004), "Características de la migración internacional en Oaxaca y sus impactos en el desarrollo regional», en Raúl Delgado Wise y Margarita Favela (coordinadores), Nuevas tendencias y desafíos de la migración internacional México-Estados Unidos, México, Miguel Ángel Porrúa, pp. 195-221.

,Antonio Yúnez Naude, Alicia Sylvia Gijón Cruz \& Raúl Hinojosa-Ojeda (2005a), "Remesas, proyectos productivos y desarrollo regional en el estado de Oaxaca», en Yolanda Massieu Trigo, Michelle Chauvet Sánchez y Rodolfo García Zamora (coordinadores), Los actores sociales frente al desarrollo rural, tomo 2, México, Editorial Praxis, pp. 223-274.

, Alicia Sylvia Gijón Cruz, Antonio Yúnez Naude y Raúl Hinojosa Ojeda (2005b), "El mito de las remesas como fuente de desarrollo local», Oaxaca: Población en el Siglo XXI, DIGEPO, año 4, núm. 13, pp. 27-34, mayo-agosto.

Robinson, Sherman, Mary E. Burfisher, Raúl Hinojosa-Ojeda y Karen E. Thierfelder (1993), «Agricultural policies and migration in a U.S-Mexico Free Trade Area: A computable general equilibrium analysis», Journal of Policy Modeling, vol. 15, núm. 5 y 6 , pp. 673-701. 
Sadoulet, Elisabeth \& Alain de Janvry (1995), Quantitative Development Policy Analysis,

U.S.A., The John Hopkins University Press.

Saluja, M. R., Basanta K. Pradhan, and Shalabh K. Singh (2006), Social Accounting Matrix for India, New Dehli, Sage Publications Inc.

SeCtur (2005), Reporte Anual, 2000-2005 con base en información generada a través del

Sistema Nacional de Información Turística (SNIT), Sistemas de Información Turística Estatal (SITE).

TAYLOR, J. Edward e Irma Adelman (1996), Village Economics: Design, Estimation, and Use of Villagewide Economic Models, U.S.A., Cambridge University Press.

VorTeVec, Steven (2006), «Trasnacionalismo migrante y formas de transformación», en

Alejandro portes y Josh De Wind (coordinadores), Repensando la migraciones. Nuevas perspectivas teóricas y empíricas, México, Miguel Ángel Porrúa, pp. 157-190.

WAGNER, John E. (1996), Developing a social accounting matrix to examine tourism in the Area de Protecao Ambiental de Guaraquecaba, Brazil, Woking Paper núm. 58, Southeastern Center for Forest Economic Reserach.

(1997), "Estimating the economic impacts of tourism», Annals of Tourism Research, vol. 24, núm. 3, Great Britain, pp. 592-608.

WORLD BANK (2002), The Next Ascent: an evaluation of the Aga Khan rural support program, Pakistan, Washington, DC, The World Bank.

(2003), Nature Tourism, Conservation, and Development in Kwazulu Natal, South Africa, Washington, DC, World Bank Publications. 